\title{
Artificial pupil versus contralateral balanced contact lens fit for presbyopia correction
}

\section{Pupila artificial vs adaptação contralateral equilibrada de lentes de contato para correção da presbiopia}

\author{
Santiago García-Lázaro ${ }^{1}$, Teresa Ferrer-Blasco ${ }^{1}$, Hema Radhakrishnan ${ }^{2}$, César Albarrán-Diego ${ }^{3}$, Robert Montés-Micó ${ }^{1}$
}

\begin{abstract}
Purpose: To assess and compare the effects of contact lens-based artificial pupil design and contralateral balanced multifocal contact lens combination (CBMCLC) on visual performance.

Methods: This randomized crossover study conducted at the University of Valencia, Spain included 38 presbyopic patients using an artificial pupil contact lens in the nondominant eye and a CBMCLC. After a month of lens wear, the binocular distance visual acuity (BDVA), binocular near visual acuity (BNVA), defocus curve, binocular distance, and near contrast sensitivity and near stereoacuity (NSA) were measured under photopic conditions $\left(85 \mathrm{~cd} / \mathrm{m}^{2}\right)$. Moreover, BDVA and binocular distance contrast sensitivity were examined under mesopic conditions $\left(5 \mathrm{~cd} / \mathrm{m}^{2}\right)$. Results: Visual acuity at an intermediate distance and near vision was better with the CBMCLC than with the artificial pupil $(p<0.05)$. Statistically significant differences were found in contrast sensitivity between the two types of correction for distance (under mesopic conditions) and for near vision, with the CBMCLC exhibiting better results in both cases $(p<0.05)$. The mean NSA values obtained for the artificial pupil contact lens were significantly worse than those for the CBMCLC ( $p=0.001)$. Conclusion: The CBMCLC provided greater visual performance in terms of intermediate and near vision compared with the artificial pupil contact lens.
\end{abstract}

Keywords: Contact lenses; Presbyopia/rehabilitation; Pupil; Prosthesis fitting dominance, ocular

\section{RESUMO}

Objetivo: Avaliar e comparar os efeitos da pupila artificial baseada em lentes de contato e a combinação equilibrada de lente de contato multifocal contralateral (CBMCLC) sobre o desempenho visual.

Métodos: Estudo realizado na Universidade de Valência, Espanha. Em um projeto de estudo do tipo "cross-over", 38 pacientes présbitas foram avaliados utilizando uma lente de contato com pupila artificial no olho não-dominante e CBMCLC. Após 1 mês, foram avaliadas, em condições fotópicas $\left(85 \mathrm{~cd} / \mathrm{m}^{2}\right)$, a acuidade visual binocular para distância (BDVA), a acuidade visual binocular para perto (BNVA), a curva de desfocagem, a sensibilidade ao contraste binocular para distância e para perto, assim como a acuidade estereoscópica para perto (NSA). Além disso, a BDVA e a sensibilidade ao contraste binocular para distância foram avaliadas em condições mesópicas $\left(5 \mathrm{~cd} / \mathrm{m}^{2}\right)$.

Resultados: A acuidade visual em distâncias intermediárias e para perto foram melhores com CBMCLC do que com pupila artificial $(p<0,05)$. Foram encontradas diferenças estatisticamente significativas entre a sensibilidade ao contraste com os dois tipos de correção para distância (em condiçoes mesópicas) e para perto, com CBMCLC ser melhor em ambos os casos $(p<0,05)$. Os valores médios da NSA obtidos $\mathrm{com}$ as lentes de contato das pupilas artificiais foram significativamente piores do que com CBMCLC $(p=0,001)$.

Conclusão: CBMCLC proporciona melhor desempenho visual para visão intermediária e para perto do que a lente de contato com pupila artificial.

Descritores: Lentes de contato; Presbiopia/reabilitação; Pupila; Ajuste de prótese; Dominância ocular

\section{INTRODUCTION}

Presbyopia is the natural decrease in accommodative ability caused by loss of elasticity of the lens of the eye. It occurs normally with aging and is first observed between 40 and 45 years of age, with a peak onset between 42 and 44 years of age ${ }^{(1,2)}$. Without optical correction, presbyopia results in the inability to perform once-effortless tasks at a customary working distance without experiencing visual symptoms ${ }^{(3)}$

A possible solution to presbyopia is wearing contact lenses. Among the different options for correcting the refractive error with contact lenses in presbyopic patients, simultaneous vision is the preferred choice for most contact lens wearers ${ }^{(4,5)}$. In simultaneous vision, the contact lens has multiple powers positioned within the pupil at the same time: a multiconcentric surface with different rings for distance and near vision, a near-center aspheric geometry, and a distance-center aspheric geometry. It is possible to combine a near-center and distance-center aspheric geometry contact lens in the same patient to emphasize the distance vision in one eye and near vision in the other. This technique, which combines multifocal optics with monovision, is known as the contralateral balanced multifocal contact lens combination (CBMCLC).

In a recent research study, García-Lázaro et al. ${ }^{(6)}$ compared 4 different designs of artificial pupil contact lenses that were fitted in the nondominant eye. This study reported good visual acuity for distance and functional intermediate vision, with no significant differences between the aperture diameters examined (from 1.6 to $3.5 \mathrm{~mm}$ ). However, it would be interesting to compare the possible benefits of the artificial pupil on visual acuity and depth-of-field for presbyopia correction with those of other techniques such as CBMCLC.

This study aimed to assess and compare the visual performance of patients fitted with the artificial pupil contact lens and CBMCLC by evaluating the binocular visual acuity, defocus curve, binocular contrast sensitivity, and near stereoacuity (NSA) measurements obtained under different illumination levels for both distance and near vision. To the best of our knowledge, this is the first study to compare the visual performance of a contact lens-based artificial pupil and CBMCLC. 


\section{METHODS}

This study was conducted in accordance with the tenets of the Declaration of Helsinki. Informed consent was obtained from all patients after the nature and possible consequences of the study had been explained. This study was approved by the institutional review board.

\section{Patients And lenses}

Thirty-eight presbyopic patients (25 females and 13 males) aged 48-62 years (54.2 \pm 5.1 years) participated in this randomized crossover study. Inclusion criteria were as follows: age between 45 and 65 years, emmetropia [cycloplegic spherical equivalent (SE), \pm 0.25 D; astigmatism, $\leq 0.50 \mathrm{D}]$, monocular best spectacle-corrected distance visual acuity $\geq 20 / 20$, and normal binocularity. Exclusion criteria were as follows: subjects with photopic $\left(85 \mathrm{~cd} / \mathrm{m}^{2}\right)$ distance pupil size $\geq 4.00 \mathrm{~mm}$, anterior segment pathology, previous intraocular or corneal surgery, cataracts, corneal abnormalities (including endothelial dystrophy, guttata, or recurrent corneal erosion), and a history of chronic dry eye, macular degeneration, retinal detachment, and/or any other fundus pathology.

Patients were randomized to be fitted with the artificial pupil or Biofinity multifocal (CooperVision, Fairport, NY) contact lenses for the first month. After a month of wear, patients returned to be refitted with the other lenses. The afocal artificial pupil contact lens was manufactured from a silicone hydrogel material with two base curve radii $(8.40$ and $8.80 \mathrm{~mm}$ ) and a $14.00-\mathrm{mm}$ lens diameter. The lens design included a $1.6-\mathrm{mm}$ central aperture in a 4- $\mathrm{mm}$ diameter opaque zone (see Figure 1). The artificial pupil systems were developed to provide functional near and intermediate vision by increasing the depth-of-field in the eye. Depth-of-field is defined as the distance in front of and beyond the object of regard that appears to be in focus. The depth-of-focus of the eye may be increased by decreasing the pupil diameter. In these patients, the dominant eye was not fitted with any contact lenses, while the nondominant eye was fitted with the artificial pupil.

The Biofinity multifocal lens is a simultaneous multifocal contact lens. This design combines spherical and aspheric optics and unique zone sizes to produce a "D" lens (center-distance design), which emphasizes distance vision, and an " $\mathrm{N}$ " lens (center-near design), which optimizes near vision. The "D" lens has a spherical central zone that is $2.3 \mathrm{~mm}$ in diameter and is dedicated to distance vision, followed by an annular aspheric zone of $5.0 \mathrm{~mm}$ and a spherical annular zone of $8.5 \mathrm{~mm}$, with both increasing the add power. In contrast, the " $\mathrm{N}$ " lens has a spherical central zone that is $1.7 \mathrm{~mm}$ and is dedicated to

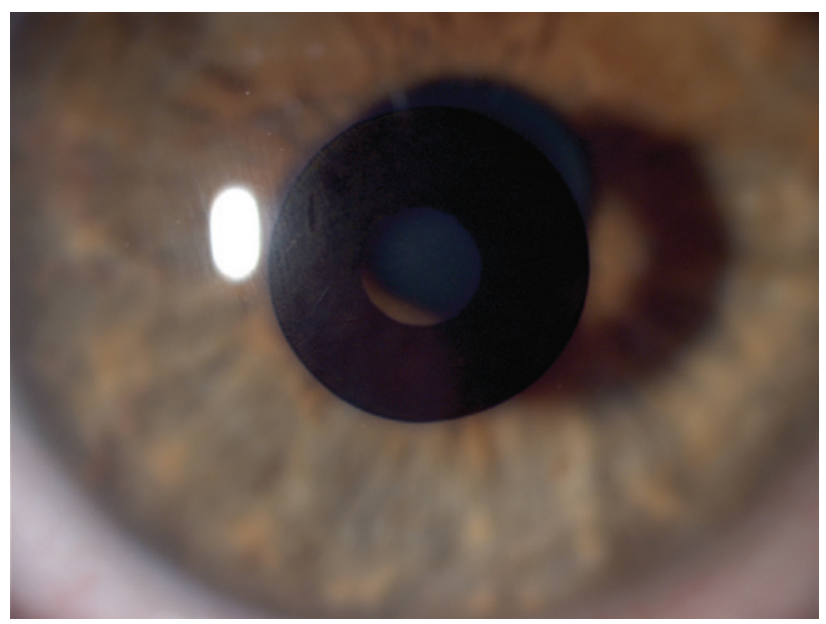

Figure 1. Design of the artificial pupil fitted. near vision, followed by an aspheric annular zone of $5.0 \mathrm{~mm}$ and an annular spheric zone of $8.5 \mathrm{~mm}$, with both decreasing the add power. Each " $\mathrm{D}$ " and " $\mathrm{N}$ " design is available from +6.00 to $-6.00 \mathrm{D}$ in $0.25-\mathrm{D}$ increments and from -6.00 to $-8.00 \mathrm{D}$ in $0.50-\mathrm{D}$ increments, as well as in 4 different add powers $(+1.00,+1.50,+2.00,+2.50)$. The lens is manufactured from Comfilcon A that has a water content of $48 \%$. The lens has a total diameter of $14.00 \mathrm{~mm}$ and a base curve of $8.60 \mathrm{~mm}$. Following the fitting nomogram suggested by CooperVision for initial lens selection, we used the "D" design in the dominant eye and the " $\mathrm{N}$ " design in the nondominant eye for all patients included in this study.

\section{Measurements}

The near add power and eye dominance were determined following the clinical protocol from the study by García-Lázaro et al.(7). The dominant eye was identified using the "plus acceptance to blur" and confirmed with the Ogle's eye dominancy test. When the two tests yielded conflicting results, a subjective approach was followed, and the lenses were fitted according to the conditions under which the subject reported the most comfortable vision. The near add power was selected on the basis of near spectacle addition [minimum spectacle addition to reach logMAR 0.0 at $40 \mathrm{~cm}$ (distance preferred by patients for reading)] and subject age (the amplitude of accommodation changes with age are predictable)(8-10).

After completion of a month of wear, the subjects returned for the assessment of visual function. The latter involved clinical assessment of visual function; the binocular distance visual acuity (BDVA), binocular near visual acuity (BNVA), defocus curve, binocular distance contrast sensitivity, binocular near contrast sensitivity, and NSA were all measured in each patient under photopic conditions $\left(85 \mathrm{~cd} / \mathrm{m}^{2}\right)$. Moreover, BDVA and binocular distance contrast sensitivity were also examined under mesopic conditions $\left(5 \mathrm{~cd} / \mathrm{m}^{2}\right)$.

BDVA was measured using the Early Treatment Diabetic Retinopathy Study (ETDRS) high-contrast logMAR chart with the Functional Vision Analyzer (FVA, Stereo Optical Company, Inc., Chicago, IL). BNVA was determined using the Precision Vision Logarithmic Visual Acuity Chart 2000 New ETDRS at $40 \mathrm{~cm}$. The through focus binocular logMAR visual acuity (defocus curve; range, $-5.00-+1.50$ D in 0.50-D increments), with randomized letter sequences and randomized lens presentations to decrease the effect of memory ${ }^{(11)}$, was also evaluated with the ETDRS high-contrast logMAR chart. NSA was determined using the Howard-Dolman system ${ }^{(12-14)}$. For the calculation of NSA values, the interpupillary distance (IPD) was measured for near vision using the Pupill'on pupillometer (Essilor Co., Ltd., France).

All near measurements were made at a distance of $40 \mathrm{~cm}$. All described procedures were then repeated for the second lens type.

\section{Data ANALYsis}

The normality of data distribution was assessed by the Shapiro-Wilk test. The null hypothesis that data came from a normally distributed population was not rejected; therefore, parametric tests were applied. Data analysis was performed using the SPSS Statistics software v.12.0 (SPSS, Chicago, IL). Paired sample t-tests were applied to test for differences between both types of correction and each of the different illumination levels. Differences were considered to be statistically significant when the $p$-value was $<0.05$.

\section{RESULTS}

The mean SE refractive error was $+0.04 \pm 0.10 \mathrm{D}$ (range, +0.25 to $-0.25 \mathrm{D})$, while the mean near spectacle addition was $+2.26 \pm$ $0.36 \mathrm{D}$ (range, 2 to $3 \mathrm{D}$ ). The difference between the values obtained by minimum spectacle addition to reach logMAR 0.0 at $40 \mathrm{~cm}$ and those reported by the guidelines for presbyopia ${ }^{(8-10)}$ were $\leq 0.25 \mathrm{D}$ in all patients. The pupil size was measured using the Colvard pupillometer (Oasis Medical, Inc., Glendora, CA). The mean pupil diameter 
was $3.55 \pm 0.23 \mathrm{~mm}$ and $4.36 \pm 0.21 \mathrm{~mm}$ under photopic $\left(85 \mathrm{~cd} / \mathrm{m}^{2}\right)$ and mesopic conditions $\left(5 \mathrm{~cd} / \mathrm{m}^{2}\right)$, respectively, for distance vision, and $3.07 \pm 0.25 \mathrm{~mm}$ and $4.02 \pm 0.18 \mathrm{~mm}$ under photopic $\left(85 \mathrm{~cd} / \mathrm{m}^{2}\right)$ and mesopic conditions $\left(5 \mathrm{~cd} / \mathrm{m}^{2}\right)$, respectively, for near vision. The near IPD at distance showed a mean value of $62.9 \pm 2.9 \mathrm{~mm}$, with a range of 58-66 $\mathrm{mm}$.

All results comparing visual acuity with the artificial pupil contact lens to that with CBMCLC are summarized in table 1. Figures 2 and 3 represent the binocular distance contrast sensitivity values obtained with both types of correction under photopic and mesopic binocular conditions, respectively. Statistically significant differences were not found between the two techniques at any spatial frequency for distance under photopic conditions ( $p>0.05$ ); however, binocular distance contrast sensitivity revealed better performance for CBMCLC than for the artificial pupil under mesopic conditions $(p<0.05)$ [statistically significant differences for 6 cycles per degree (cpd), $12 \mathrm{cpd}$ and $18 \mathrm{cpd}]$. Figure 4 displays the contrast sensitivity values obtained for binocular near vision under photopic conditions. CBMCLC showed significantly better contrast sensitivity values for this distance. Statistically significant differences were found between the two types of correction for contrast sensitivity for near vision at all spatial frequencies tested ( $p<0.05)$, except for $1.5 \mathrm{cpd}(p=0.48)$.

Figure 5 shows the mean binocular visual acuity measurements as a function of defocus for the artificial pupil contact lens and CBMCLC. The defocus curve showed a peak of optimum distance vision, $0.00 \pm$ 0.05 and $-0.03 \pm 0.07 \log M A R$, for the artificial pupil contact lens and CBMCLC, respectively, at the vergence of $0 \mathrm{D}$. Statistical analysis sho- wed no significant differences between both systems at this vergence $(p=0.08)$. When negative lenses were introduced from a vergence of $0 \mathrm{D}$, a continuous deterioration was observed with both techniques at all steps. The defocus curve showed that CBMCLC was significantly better than the artificial pupil contact lens for intermediate and near distance vision. Significant differences between both corrections of presbyopia for intermediate distance vision (lens power, from -1.00 D to $-2.00 \mathrm{D}$, corresponding to optical distances between $50 \mathrm{~cm}$ and $100 \mathrm{~cm} ; p<0.05$ ) and near vision (lens power, $-2.50 \mathrm{D} ; p<0.05$ ). In all patients, when statistically significant differences were found for the negative values of defocus, the mean visual acuities values were better with CBMCLC.

The average NSA values were significantly better with CBMCLC than with the artificial pupil contact lens ( $235 \pm 28$ and $147 \pm 41 \mathrm{sec}$ arc, respectively; $p<0.01$ ).

\section{DISCUSSION}

In this study, we evaluated two possible solutions for presbyopia through contact lenses. These two techniques were based on different monocular optical principles to achieve focus at different distances (aspheric design for CBMCLC and increasing the depth of focus for artificial pupil contact lens); however, both solutions further emphasized distance vision in the dominant eye and near vision in the nondominant eye for binocular vision. This selection that emphasized distance vision for binocular conditions can explain the favorable results in distance vision because the best monocular

Table 1. Summary of visual acuity between artificial pupil design and contralateral balanced multifocal contact lens combination. In each case the mean and standard deviation of all subjects is given

\begin{tabular}{lccc}
\hline & \multicolumn{3}{c}{ Mean \pm standard deviation by type of contact lens correction } \\
\cline { 2 - 3 } & Artificial pupil & Contralateral balanced multifocal contact lens combination & $\boldsymbol{p}$-value \\
\hline BDVA photopic (logMAR) & $0.01 \pm 0.06$ & $-0.03 \pm 0.07$ & 0.11 \\
BDVA mesopic (logMAR) & $0.16 \pm 0.08$ & $0.12 \pm 0.06$ & 0.07 \\
BNVA photopic (logMAR) & $0.33 \pm 0.16$ & $0.19 \pm 0.10$ & $0.001^{*}$ \\
\hline
\end{tabular}

$\mathrm{BDVA}=$ binocular distance visual acuity; $\mathrm{BNVA}=$ binocular near visual acuity.

* = statistically significant difference.

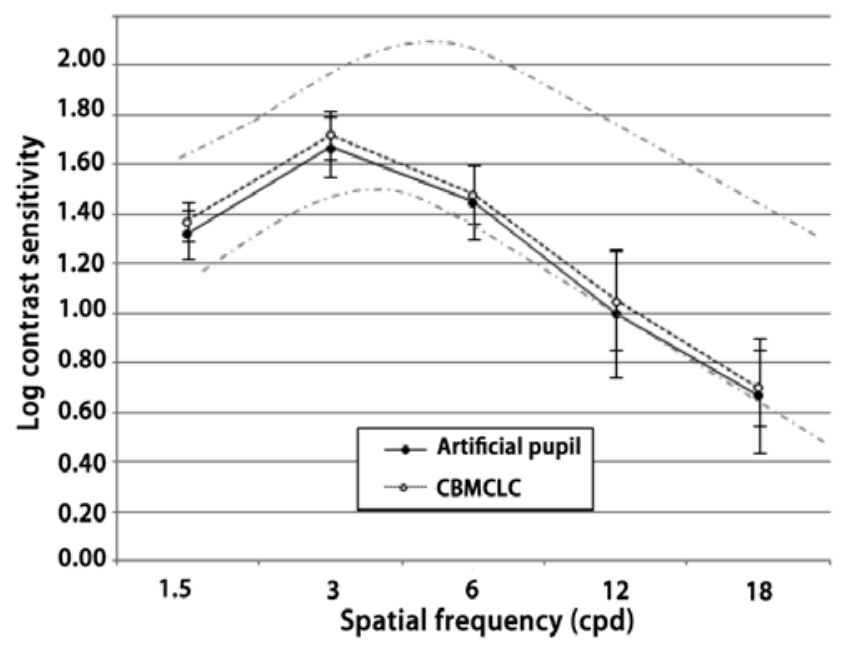

$\mathrm{CBMCLC}=$ contralateral balanced multifocal contact lens combination.

Figure 2. Binocular photopic log contrast sensitivity function $\left(85 \mathrm{~cd} / \mathrm{m}^{2}\right)$ for distance for the artificial pupil design and the balanced presbyopic contact lens. The $y$-axis shows the log contrast sensitivity and the $x$-axis shows the spatial frequencies in cycles per degree (cpd). Error bars represent the standard deviation from the means. Gray lines are the age-correlated norm values.

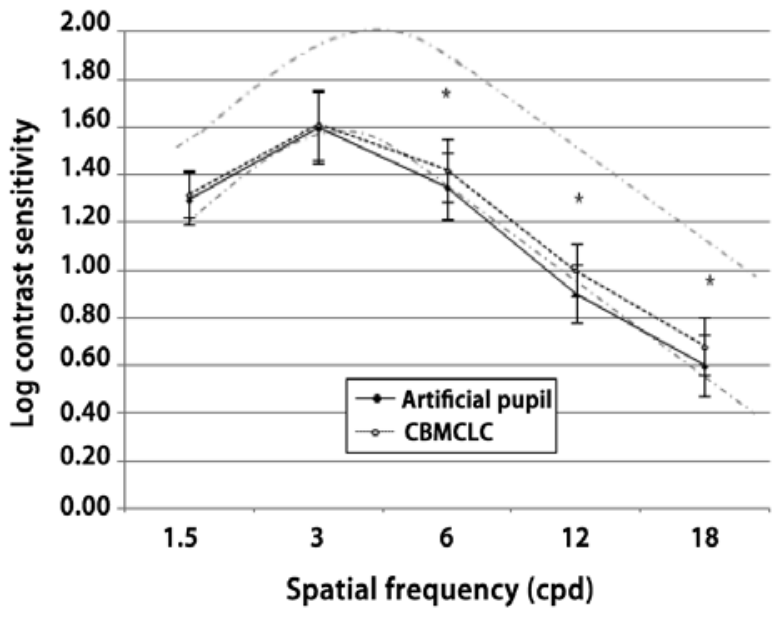

* = statistically significant differences between both systems. $\mathrm{CBMCLC}=$ contralateral balanced multifocal contact lens combination.

Figure 3. Binocular mesopic log contrast sensitivity function $\left(5 \mathrm{~cd} / \mathrm{m}^{2}\right)$ for distance vision for the artificial pupil design and the balanced presbyopic contact lens. The $y$-axis shows the log contrast sensitivity and the $x$-axis shows the spatial frequencies in cycles per degree (cpd). Error bars represent the standard deviation from the means. Gray lines are the age-correlated norm values. 


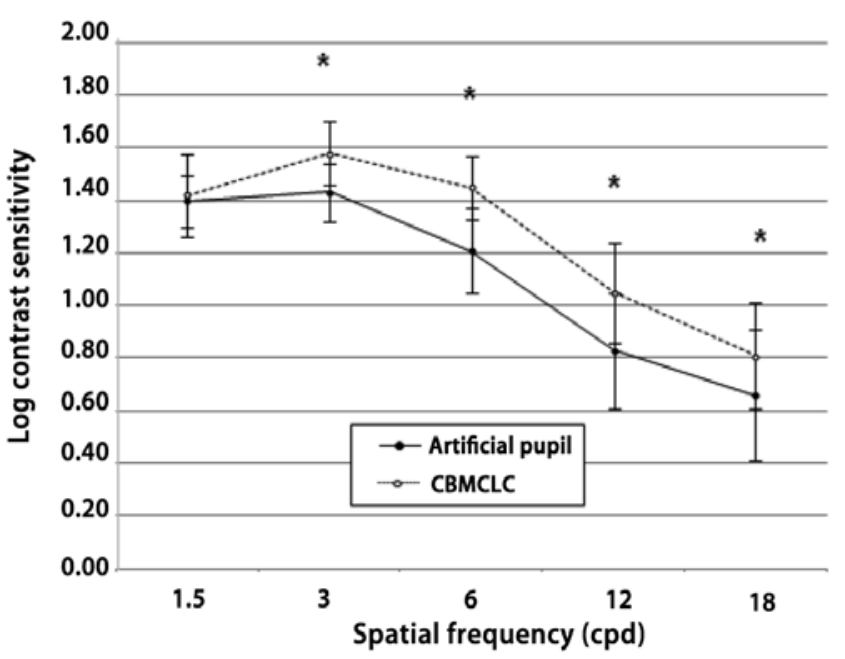

$\mathrm{CBMCLC}=$ contralateral balanced multifocal contact lens combination . * = statistically significant differences between both systems.

Figure 4. Binocular photopic log contrast sensitivity function $\left(85 \mathrm{~cd} / \mathrm{m}^{2}\right)$ for near vision for the artificial pupil design and the balanced presbyopic contact lens. The $y$-axis shows the log contrast sensitivity and the $\mathrm{x}$-axis shows the spatial frequencies in cycles per degree (cpd). Error bars represent the standard deviation of the means.

input would be responsible for conducting binocular visual acuity tasks. The BDVA values obtained in this study were coincident with those previously reported in patients fitted with $\mathrm{CBMCLC}^{(13,15)}$ (Proclear Multifocal of Cooper Vision) or those fitted with artificial pupil contact lenses $^{(7)}$. Moreover, our results were consistent with those of research conducted in patients implanted with a artificial pupil in a corneal inlay for correcting presbyopia ${ }^{(16,17)}$ or simulated pinholes using adaptive optics ${ }^{(18)}$ under photopic conditions.

The add power in the aspheric multifocal contact lenses and the near-center design of lenses placed in the nondominant eye provided better performance compared with the monocular increased depth-of-field in the artificial pupil contact lenses in near vision. The results for the artificial pupil contact lens reported here are in agreement with the results of recently reported studies that compared pinhole contact lenses ${ }^{(6)}$ and artificial pupil contact lenses (1.6-mm central aperture in a 4-mm diameter opaque zone) with monovision ${ }^{(7)}$ or using adaptive optics ${ }^{(18)}$. In contrast, at least 3 studies using intracorneal inlays reported better BNVA values compared with those found in our study ${ }^{(16,17,19)}$. These differences may be due to the increased transmission of visible light because of the 1.600 small holes (25- $\mu$ m diameter) arranged in a randomized pattern of small perforations in the intracorneal inlay (Kamra intracorneal inlay). These holes allowed the light to pass, with an average light transmission of $7.1 \%$ through the annulus of the inlay ${ }^{(16)}$. This disagreement also occurred in previous studies performed with CBMCLC ${ }^{(13)}$ or simultaneous vision multifocal contact lenses ${ }^{(5,12,20,21)}$. Probably, this disparity in results was related to the different techniques, design of lenses, and adaptation criteria.

Contrast sensitivity is a very important measurement for patients fitted with contact lenses for presbyopia and allows for the detection of subtle changes in visual quality that may not be detected by any other measurement. Our results, in terms of binocular contrast sensitivity, were consistent with those reported previously using the artificial pupil contact lens ${ }^{(6,7)}$. Unfortunately, no previous studies analyzed contrast sensitivity in patients with CBMCLC; therefore, a direct comparison with other reports was not possible. Nevertheless, we can compare our results with those for other simultaneous vision multifocal lenses (with other surface designs). The CBMCLC results reported here were in agreement with those reported by other authors
Defocus (D)

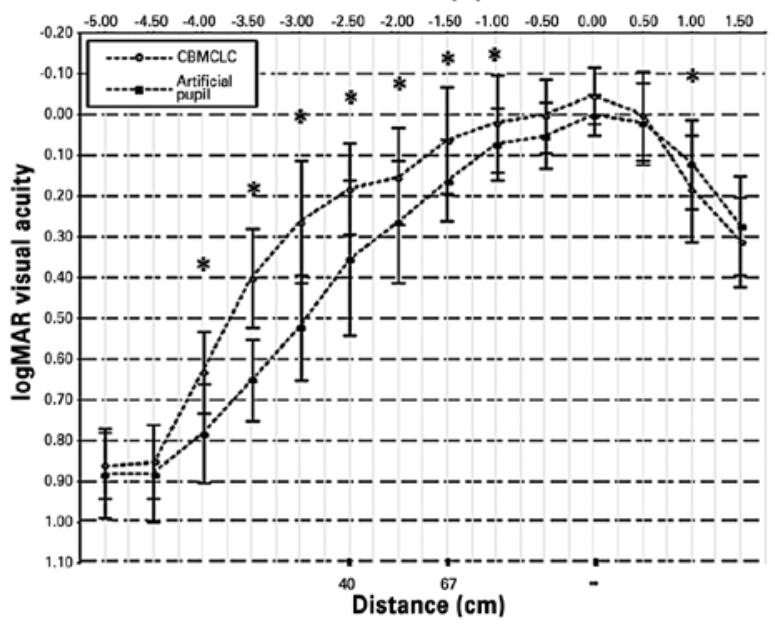

$\mathrm{CBMCLC}=$ contralateral balanced multifocal contact lens combination . *= statistically significant differences between both systems.

Figure 5. Defocus curve for the artificial pupil design and the contralateral balanced multifocal contact lens combination. The $y$-axis shows visual acuity (logMAR) and the $\mathrm{x}$-axis shows vergence (top, diopters; bottom, $\mathrm{cm}$ ). Error bars represent the standard deviation of the means.

using simultaneous vision contact lenses with a center-near design (PureVision multifocal)(20-22). The differences in binocular contrast sensitivity between the artificial pupil and CBMCLC strategies in our study may be due to the greater effect of increased retinal blur from the defocus in the artificial pupil contact lens compared with that from the superimposed images in CBMCLC.

Intermediate vision can be crucial (for example, most of the tasks performed with a computer require good intermediate vision) because of the current lifestyles of presbyopic patients. Therefore, any presbyopic solution should give the patients a wide range of vision. In order to do that, previous studies have shown that the defocus curve may be an effective method to assess the clear range of vision in patients with simultaneous vision multifocal contact lenses ${ }^{(21)}$. In the present research, the visual acuity from -1.00 to $-4.00 \mathrm{D}$ (these vergences are equivalent to a distance from 100 to $25 \mathrm{~cm}$ ) was significantly better with CBMCLC than with the artificial pupil contact lens (Figure 5). These results obtained with pinhole contact lenses were consistent with the outcomes reported previously with artificial pupil contact lenses ${ }^{(6,7)}$ or after intracorneal implantation ${ }^{(16,17)}$. There are no previous studies on the defocus curve of the CBMCLC technique in presbyopic patients for comparison with our results. With regard to simultaneous vision multifocal contact lenses, Gupta et al. ${ }^{(21)}$ had reported visual acuity values of $0.30 \pm 0.10 \log$ MAR at $80 \mathrm{~cm}$ with the PureVision multifocal contact lens, while in the present study, the acuities were approximately 0.03 logMAR with CBMCLC for the same distance. This difference between both multifocal studies could be due to the use of a center-distance and center-near design in the dominant and nondominant eyes, respectively, with CBMCLC, as opposed to the use of a center-near design in both eyes with PureVision multifocal contact lenses.

The NSA may be measured using different tests, and the practitioner must select the one that is appropriate for each situation. The Howard-Dolman apparatus accurately analyzes the stereoscopic threshold in contrast to more commercial and clinically used vectographic tests such as the Titmus and Random Dot. The Titmus and Random Dot stereotests provide fixed disparities; therefore, the accuracy of the outcomes depends on the number of steps and their disparity levels. Instead, the Howard-Dolman method gives a continuous measure of NSA with high accuracy. The differences 
between the two systems were consistent with those obtained in terms of visual acuity and contrast sensitivity in patients with near vision. Previous studies have analyzed the effects of artificial pupils placed in one eye at the NSA threshold under binocular conditions and have shown similar outcomes ${ }^{(6,7)}$. The CBMCLC results reported here were in disagreement with those reported by the only study that analyzed NSA in patients fitted with CBMCLC ${ }^{(13)}$. Ferrer-Blasco et al. ${ }^{(13)}$ found $22.40 \pm 8.23,56.40 \pm 18.00$, and $54.80 \pm 20.23 \mathrm{sec}$ of $\operatorname{arc}$ in 25 patients fitted with Proclear multifocal lenses from Cooper Vision using the Howard-Dolman, Titmus, and Random Dot sterereotests, respectively. Previous studies have analyzed NSA in patients fitted with different models of multifocal contact lenses with the same ${ }^{(12,22)}$ or different stereotests ${ }^{(5,21,23-25)}$. Considering all these previous studies, there has been some variability among results. The use of different stereotests and the design of the lenses (concentric or aspheric and add power) with the consequent image created on the retina made these differences plausible.

In summary, the present study assessed and compared the effects of the contact lens-based artificial pupil design and CBMCLC on visual performance. The results of this study suggested that for presbyopes, CBMCLC provided better performance in terms of intermediate and near vision compared with the artificial pupil contact lens. The combined design of multifocal optics with monovision may be more appropriate than contact lenses based on the depth-of-field under real-life conditions.

\section{REFERENCES}

1. Kleinstein RN. Epidemiology of presbyopia. In: Stark L, Obrecht G, editors. Presbyopia. New York: Professional Press; 1987. p.12-8.

2. Ferrer-Blasco T, González-Méijome JM, Montés-Micó R. Age-related changes in the human visual system and prevalence of refractive conditions in patients attending an eye clinic. J Cataract Refract Surg. 2008;34(3):424-32.

3. Patorgis CJ. Presbyopia. In: Amos JF, editor. Diagnosis and management in vision care. Boston: Butterworths; 1987. p.203-38.

4. Morgan PB, Efron N, Woods CA; International Contact Lens Prescribing Survey Consortium. An international survey of contact lens prescribing for presbyopia. Clin Exp Optom. 2011;94(1):87-92.

5. Richdale K, Mitchell GL, Zadnik K. Comparison of multifocal and monovision soft contact lens corrections in patients with low-astigmatic presbyopia. Optom Vis Sci. 2006;83(5):266-73.
6. García-Lázaro S, Ferrer-Blasco T, Radhakrishnan H, Cerviño A, Charman WN, Montés-Micó R. Visual function through 4 different contact-lens based pinhole systems for presbyopia. J Cataract Refract Surg. 2012;38(5):858-65.

7. García-Lázaro S, Ferrer-Blasco T, Radhakrishnan H, Albarrán-Diego C, Montés-Micó R. Visual comparison of an artificial pupil contact lens to monovisión. Optom Vis Sci. 89(7):E1022-9

8. Borish IM. Clinical Refraction. Chicago: Professional Press; 1970. p.355.

9. Hanlon SD, Nakabayashi L Shigezawa G. A critical review of presbyopic add determination. J Am Optom Assoc. 1987;58(6):468-72.

10. Woo GC, Sivak IG. A comparison of three methods for determining the reading addition. Am J Optom Pnysiot Opt. 1979;56(2):75-7.

11. Gupta N, Naroo SA, Wolffsohn JS. Is randomisation necessary for measuring defocus curves in pre-presbyopes? Cont Lens Anterior Eye. 2007;30(2):119-24.

12. Ferrer-Blasco T, Madrid-Costa D. Stereoacuity with simultaneous vision multifocal contact lenses. Optom Vis Sci. 2010;87(9):E663-8.

13. Ferrer-Blasco T, Madrid-Costa D. Stereoacuity with balanced presbyopic contact lenses. Clin Exp Optom. 2011;94(1):76-81.

14. Ferrer-Blasco T, Madrid-Costa D, García-Lázaro S, Cerviño A, Montés-Micó R. Stereopsis in bilaterally multifocal pseudophakic patients. Graefes Arch Clin Exp Ophthalmol. 2011;249(2):245-51.

15. Sanders $\mathrm{E}$, Wagner $\mathrm{H}$, Reich LN. Visual acuity and balanced progressive simultaneous vision multifocal contact lenses. Eye Contact Lens. 2008;34(5):293-6.

16. Yilmaz OF, Bayraktar S, Agca A, Yilmaz B, McDonald MB, van de Pol C. Intracorneal inlay for the surgical correction of presbyopia. J Cataract Refract Surg. 2008:34(11):1921-7.

17. Seyeddain O, Riha W, Hohensinn M, Nix G, Dexl AK, Grabner G. Refractive surgical correction of presbyopia with the AcuFocus small aperture corneal inlay: two-year follow-up. J Refract Surg. 2010;26(10):707-15.

18. Tabernero J, Schwarz C, Fernández EJ, Artal P. Binocular visual simulation of a cornea inlay to increase depth of focus. Invest Ophthalmol Vis Sci. 2011;52(8):5273-7.

19. Yılmaz OF, Alagöz N, Pekel G, Azman E, Aksoy EF, Cakır H, Bozkurt E, Demirok A. Intracorneal inlay to correct presbyopia: Long-term results. J Cataract Refract Surg. 2011; 37(7):1275-81

20. Llorente A, García-Lázaro S, Ferrer-Blasco T, Pérez -Cambrodí RJ, Cerviño A. Visua performance with simultaneous vision multifocal contact lenses. Clin Exp Optom. 2011,95(1):54-9.

21. Gupta N, Naroo SA, Wolffsohn JS. Visual comparison of multifocal contact lens to monovision. Optom Vis Sci. 2009;86(2):98-105.

22. García-Lázaro S, Ferrer-Blasco T, Radhakrishnan H, Albarrán-Diego C, Montés-Micó R. Visual performance comparison between contact-lens based pinhole and simultaneous vision contact lenses. Clin Exp Optom. 2013;96(1):46-52.

23. Back A, Grant T, Hine N. Comparative visual performance of three presbyopic contact lens corrections. Optom Vis Sci. 1992;69(6):474-80.

24. Woods J, Woods CA, Fonn D. Early symptomatic presbyopes-what correction modality works best? Eye Contact Lens. 2009;35(5):221-6.

25. Kirschen DG, Hung CC, Nakano TR. Comparison of suppression, stereoacuity, and interocular differences in visual acuity in monovision and acuvue bifocal contact lenses. Optom Vis Sci. 1999;76(12):832-7. 